\title{
40-Hz steady state response in Alzheimer's disease and mild cognitive impairment
}

Citation for published version (APA):

van Deursen, J. A., Vuurman, E. F. P. M., van Kranen-Mastenbroek, V. H. J. M., Verhey, F. R. J., \& Riedel, W. J. (2011). 40-Hz steady state response in Alzheimer's disease and mild cognitive impairment. Neurobiology of Aging, 32(1), 24-30. https://doi.org/10.1016/j.neurobiolaging.2009.01.002

Document status and date:

Published: 01/01/2011

DOI:

10.1016/j.neurobiolaging.2009.01.002

Document Version:

Publisher's PDF, also known as Version of record

Document license:

Taverne

\section{Please check the document version of this publication:}

- A submitted manuscript is the version of the article upon submission and before peer-review. There can be important differences between the submitted version and the official published version of record.

People interested in the research are advised to contact the author for the final version of the publication, or visit the DOI to the publisher's website.

- The final author version and the galley proof are versions of the publication after peer review.

- The final published version features the final layout of the paper including the volume, issue and page numbers.

Link to publication

\footnotetext{
General rights rights.

- You may freely distribute the URL identifying the publication in the public portal. please follow below link for the End User Agreement:

www.umlib.nl/taverne-license

Take down policy

If you believe that this document breaches copyright please contact us at:

repository@maastrichtuniversity.nl

providing details and we will investigate your claim.
}

Copyright and moral rights for the publications made accessible in the public portal are retained by the authors and/or other copyright owners and it is a condition of accessing publications that users recognise and abide by the legal requirements associated with these

- Users may download and print one copy of any publication from the public portal for the purpose of private study or research.

- You may not further distribute the material or use it for any profit-making activity or commercial gain

If the publication is distributed under the terms of Article $25 \mathrm{fa}$ of the Dutch Copyright Act, indicated by the "Taverne" license above, 


\title{
40-Hz steady state response in Alzheimer's disease and mild cognitive impairment
}

\author{
J.A. van Deursen ${ }^{a, b}$, E.F.P.M. Vuurman ${ }^{\text {a,b,*, V.H.J.M. van Kranen-Mastenbroek }}{ }^{c}$, \\ F.R.J. Verhey ${ }^{\mathrm{a}}$, W.J. Riedel ${ }^{\mathrm{b}}$ \\ a Dept. of Psychiatry and Neuropsychology, Faculty of Health, Medicine and Life Sciences, Maastricht University, The Netherlands \\ ${ }^{\mathrm{b}}$ Dept. of Neuropsychology \& Psychopharmacology, Faculty of Psychology, Maastricht University, The Netherlands \\ ${ }^{\mathrm{c}}$ Dept. of Clinical Neurophysiology, University Hospital Maastricht, The Netherlands \\ Received 24 October 2008; received in revised form 22 December 2008; accepted 1 January 2009 \\ Available online 23 February 2009
}

\begin{abstract}
The 40-Hz steady state response (SSR) reflects early sensory processing and can be measured with electroencephalography (EEG). The current study compared the 40-Hz SSR in groups consisting of mild Alzheimer's disease patients (AD) ( $n=15)$, subjects with mild cognitive impairment (MCI) $(n=20)$ and healthy elderly control subjects $(n=20)$. All participants were naïve for psychoactive drugs. Auditory click trains at a frequency of $40-\mathrm{Hz}$ evoked the $40-\mathrm{Hz}$ SSR. To evaluate test-retest reliability (TRR), subjects underwent a similar assessment 1 week after the first. The results showed a high TRR and a significant increase of 40-Hz SSR power in the AD group compared to MCI and controls. Furthermore a moderate correlation between $40-\mathrm{Hz}$ SSR power and cognitive performance as measured by ADAS-cog was shown.

The results suggest that $40-\mathrm{Hz}$ SSR might be an interesting candidate marker of disease progression.

(C) 2009 Published by Elsevier Inc.
\end{abstract}

Keywords: Alzheimer's disease; MCI; EEG; 40-Hz; Steady state response; Cortical inhibition; Reliability; Neurophysiology

\section{Introduction}

Cortical neural activity is reflected in the electroencephalogram (EEG). Fast neural oscillations measured with EEG and magnetoencephalography (MEG) have been proposed to be an important mechanism in the integration and binding of neural networks in perceptual and cognitive processes (Herrmann et al., 2004; Joliot et al., 1994; Tallon-Baudry and Bertrand, 1999).

A basic method for measuring these fast oscillations is by evoking a $40-\mathrm{Hz}$ steady state response (SSR). The $40-\mathrm{Hz}$ SSR is elicited by auditory stimulation with "click trains" at 40-Hz.

These very short individual clicks each evoke an eventrelated response (ERP). The short inter-stimulus intervals in

\footnotetext{
* Corresponding author at: Department of Psychiatry and Neuropsychology, Faculty of Health, Medicine and Life Sciences, Maastricht University, P.O. Box 616, 6200 MD Maastricht, The Netherlands. Tel.: +31 433881046.

E-mail address: E.Vuurman@np.unimaas.nl (E.F.P.M. Vuurman).
}

the click trains do not allow the ERP's to return to baseline, resulting in a nearly sinusoidal SSR (Tallon-Baudry and Bertrand, 1999). As a result, the $40-\mathrm{Hz}$ SSR can be considered as a superimposition of middle-latency responses (P50) to each individual click (Galambos et al., 1981). Early gamma band responses such as the 40-Hz SSR are involved in the sensory processes that precede perceptual or attentional processes (Karakas and Basar, 1998).

Impaired sensory processing is one of the hallmarks of Alzheimer's disease (AD).

A study using magnetoencephalography showed that the $40-\mathrm{Hz}$ SSR in a drug naïve AD population is enhanced compared to that in healthy controls (Osipova et al., 2006). Osipova et al. related their findings to decreased cortical inhibition in AD. This explanation is substantiated by results from studies using a sensory gating or dual-click paradigm. This paradigm involves the presentation of two consecutive clicks, whereby the P50 amplitude to the second click should be lower. This paradigm is considered a measure for cortical inhibition. Several studies have shown that subjects with 
AD diverged from the paradigm and exhibited increased P50 amplitude to the second click in AD (Cancelli et al., 2006; Jessen et al., 2001). A study that examined healthy volunteers with a family history of $\mathrm{AD}$ also showed a similar divergence in the P50 amplitude (Boutros et al., 1995). This suggests that impaired cortical inhibition may be present very early in the course of the disease. With a view to detecting the disease at an early stage, it is important to identify whether the difference in the $40-\mathrm{Hz}$ rhythm is already present in a well-defined MCI population.

The current study aims to examine whether differences, similar to the findings of Osipova et al. (2006) are revealed when EEG is used to study AD patients. Furthermore, it sets out to discover whether these differences are already present in subjects with MCI. The current study reports data from a psychoactive drug naïve population. This is an important methodological issue since several studies showed that pharmacological modulations have a profound effect on the power of the 40-Hz rhythm (Ahveninen et al., 1999, 2002).

To evaluate the robustness and reproducibility of the results, the test-retest reliability (TRR) of the $40-\mathrm{Hz}$ SSR paradigm will be evaluated.

We hypothesized that the $40-\mathrm{Hz}$ SSR is enhanced in patients with AD compared to subjects with MCI and healthy controls. Furthermore, it is to be expected that the SSR in the MCI group will be higher than in the control group, but lower than in the $\mathrm{AD}$ group.

\section{Materials and methods}

\subsection{Subjects}

The study included three different groups of subjects:

(1) Fifteen psychoactive drug naïve patients with a diagnosis of probable AD according to the NINCDS-ADRDA criteria were included (McKhann et al., 1984).

(2) Twenty psychoactive drug naïve patients with a diagnosis of MCI according to the Petersen criteria were included (Petersen et al., 2001). MCI subjects also received standard blood workup, neuro-imaging and neuropsychological testing. The diagnosis $\mathrm{AD}$ or $\mathrm{MCI}$ was made at a weekly consensus meeting of different specialists. The diagnostic assessment included the following: a detailed history-taking of the subjects; a psychiatric, neurological and physical examination; the Mini Mental State Examination (MMSE) (Folstein et al., 1975); CAMDEX part-B (CAMCOG) (Derix et al., 1991); an assessment using clinical rating scales (i.e. GDS) (Reisberg et al., 1982), the Hamilton Depression scale (Hamilton, 1960) and the Blessed Dementia Rating scale (Blessed et al., 1968); appropriate laboratory tests (i.e. haematology, glucose, biochemical analysis, vitamin B12 and thyroid stimulating hormone); a neuropsychological assessment including tests covering the domains of memory, attention, executive functioning, language, praxis and intelligence and CT or MRI imaging as described elsewhere (Verhey et al., 1993).

(3) Twenty healthy control subjects were recruited from the Maastricht Aging Study (MAAS), a longitudinal study of the determinants of healthy cognitive aging (van Boxtel et al., 1998). The control subjects were not using any psychoactive medications. Their medical history was screened by a medical health questionnaire. Main exclusion criteria were: a history of stroke, head trauma, and/or any other neurological or psychiatric disorders. Additional exclusion criteria were: severe cardiovascular disease, a Hachinski Ischemic Scale (HIS) (Hachinski et al., 1974; Rosen et al., 1980) higher than three or a history of substance abuse and/or other serious system diseases (e.g. malignancy, uncontrolled hypertension, neuropathy or seizure disorders).

All AD and MCI patients were recruited at the Memory Clinic of the Maastricht University Hospital and were judged competent to give consent by their treating physicians. This study was carried out in accordance with the declaration of Helsinki. All participants gave written informed consent prior to the study and in the case of the AD patients a family member also signed the consent form. The local Medical Ethics Committee of the Maastricht University Hospital approved the study.

\subsection{Experimental procedure}

All subjects took part in two identical recording sessions, temporally spaced apart by 1 week. All subjects were required to abstain from alcohol, nicotine and caffeine, from 08:00 $\mathrm{pm}$, the evening prior to the test sessions. All subjects were tested between 09:00 am and 5:00 pm. On both occasions, the cognitive subscale of the Alzheimer's Disease Assessment Scale (ADAS-cog) (Rosen et al., 1984; Verhey et al., 2004) was assessed prior to EEG acquisition. The Dutch version of the National Adult Reading Test (NART) (Schmand et al., 1998) was assessed to estimate pre-morbid intelligence. The $40-\mathrm{Hz}$ steady state response was part of a larger study, which further included: induced gamma band measurement; contingent negative variation (CNV); checkerboard task; and an oddball paradigm. Headphones were used to present the auditory stimuli.

To evaluate the robustness of the results the test-retest reliability was evaluated. Therefore subjects visited our facilities twice for similar assessments with an interval of 1 week.

\subsection{Stimulation}

In the current study there were two conditions; auditory 40-Hz stimulation and resting state.

During EEG recording the subjects were presented with 1 -ms clicks at a frequency of $40-\mathrm{Hz}$. Headphones presented 80 click trains of $450 \mathrm{~ms}$ binaurally. Subjects were instructed 
to focus on a white crosshair in the centre of a black screen during the $40-\mathrm{Hz}$ stimulation. During the resting state condition, subjects were instructed to keep their eyes open and focus on a white crosshair on a black screen for $90 \mathrm{~s}$.

\subsection{EEG acquisition}

EEG was recorded on a commercially available EEG acquisition system $\left(\mathrm{Nuamps}^{\circledR}\right)$. Electrodes $(\mathrm{AgCl})$ were positioned following the 10-20 system on a 32-channel electrode cap, using 19 electrodes $\left(\right.$ Medcat $\left.{ }^{\circledR}\right)$. A low-pass filter of $100 \mathrm{~Hz}$ and a high-pass filter of $0.1 \mathrm{~Hz}$ were applied. The sample frequency was $512 \mathrm{~Hz}$ and analogue-digital conversion was 20 bit. Electrode impedance was kept below $5 \mathrm{k} \Omega$. A reference electrode was placed on the right ear lobe. To control for possible vertical eye movements, an electro-oculogram (EOG) electrode was placed $1 \mathrm{~cm}$ under the midline of the right eye. A ground electrode was placed on the forehead, at Fpz position.

EEG's were recorded in a magnetically shielded and sound-attenuated room. During EEG recording subjects were instructed to focus on a white crosshair on a black screen. Subjects were able to see the screen through magnetically shielded glass. Neuroscan ${ }^{\circledR} 4.3$ software was used for EEG recording and analyses.

\subsection{0-Hz SSR analysis}

EEG analysis was performed off-line. Epochs were recorded in two conditions, during stimulation and during resting state, each with a length of $450 \mathrm{~ms}$. Epochs containing eye movements, electromyographic activity (EMG), or head motion artefacts were omitted from analysis. Since EMG activity is in the same frequency spectrum as gamma band activity (Whitham et al., 2007), extra effort was taken to remove the EMG activity from the data. This procedure is described in more detail in van Deursen et al. (2008). As a result the 40-Hz SSR data reported here is completely free of EMG activity. Further pre-processing procedures included; band-pass filtering (35-45 Hz, $48 \mathrm{~dB} /$ oct) and baseline correction. The mean number of uncontaminated epochs that were included in the analysis was 58 (S.D. 13.9) for the AD group, 59 (S.D. 10.7) for the MCI group and 61 (S.D. 11.6) for the control group. The number of uncontaminated epochs did not differ between the groups $\left(F_{2,52}=.72, p=.49\right)$. The uncontaminated epochs were transformed from the temporal domain to the frequency domain using fast-Fourier transformation $(1 \mathrm{~Hz}$ resolution, 512 point block-size, Hanning window $35-45 \mathrm{~Hz}$ ). The mean power at $40-\mathrm{Hz}$ was calculated for each subject and each session.

\subsection{Statistics}

Significance levels associated with the differences in 40$\mathrm{Hz}$ SSR power between the AD, MCI and control groups were calculated using ANOVA for repeated measures. Elec- trode position was used as a within-subject variable. Since $40-\mathrm{Hz}$ power was measured in two sessions the mean of these sessions was used in the ANOVA analysis. Post hoc Bonferonni correction for multiple comparisons was used. To evaluate the effect of stimulation compared to resting state, ANOVA for repeated measures was used with condition as a within-subject variable.

To examine TRR, a paired samples $t$-test was used to evaluate potential differences between the two sessions for the Fz, $\mathrm{Cz}$ and Pz electrode. Furthermore, Pearson's correlation coefficient between the sessions was calculated at $\mathrm{Fz}, \mathrm{Cz}$ and $\mathrm{Pz}$. These analyses were done for each patient group separately.

To examine the relation between $40-\mathrm{Hz}$ power and cognitive performance as measured by ADAS-cog, Pearson's correlation coefficient between these variables was calculated.

\section{Results}

\subsection{Subjects' demographics}

Fifteen AD patients were included. They had a mean age of 75.2 (S.D. 6.9) and a mean MMSE of 20.8 (S.D. 2.7, range 17-26). Eleven of the AD patients were male.

Twenty MCI patients were included. They had a mean age of 70.6 (S.D. 7.2) and a mean MMSE of 26.3 (S.D. 1.6, range 23-29). Twelve of the MCI patients were male.

Twenty healthy control subjects were included. They had a mean age of 69.5 (S.D. 6.1) and a mean MMSE of 29.3 (S.D. 0.8 , range 28-30). Twelve of the healthy control subjects were male. ANOVA analysis showed no statistical differences between the groups in age $\left(F_{2,52}=2.2, p=.14\right)$. However, when the age differences are studied in more detail with a $t$-test, there is a small difference between the AD and controls group $\left(t_{1,33}=2.59, p=.0143\right)$. Pre-morbid intelligence as estimated by NART, did not differ $\left(F_{2,52}=1.7, p=.20\right)$ between the groups.

\subsection{Test-retest reliability}

Table 1 presents the results of the TRR analysis.

The paired samples $t$-test between the sessions showed a significant difference in the $\mathrm{AD}$ group at $\mathrm{Fz}\left(t_{15,1}: 2.42\right.$; $p=.032)$, and in the MCI group at $\mathrm{Fz}\left(t_{19,1}: 3,37 ; p=.004\right), \mathrm{Pz}$ $\left(t_{19,1}: 3,44 ; p=.003\right)$ and $\mathrm{Cz}\left(t_{19,1}: 3,42 ; p=.003\right)$. Despite the significant differences in the $t$-test the correlation coefficient was high in all groups and in all electrodes.

\subsection{0-Hz steady state response}

The results of the 40-Hz power analysis during stimulation condition and resting state are presented in Fig. 1.

During stimulation condition ANOVA analysis showed that the $40-\mathrm{Hz}$ SSR differed between the groups at T5 $\left(F_{52,2}\right.$ : $3.46 ; p=.034)$, $\mathrm{T} 6\left(F_{52,2}: 7.20 ; p=.002\right)$ and $\mathrm{O} 2\left(F_{52,2}: 4.29\right.$; 
$p=.019)$. Bonferonni post hoc analysis for multiple comparisons showed that the $40-\mathrm{Hz}$ power was higher in the AD group compared to controls at $\mathrm{T} 5, \mathrm{~T} 6$ and $\mathrm{O} 2$. There was a significant difference between $\mathrm{AD}$ and MCI only at T6. There were no significant differences between the MCI and control group during the stimulation condition.

To ensure that the differences are related to the task and are not due to aspects of the resting state, the effect of stimulation was examined using ANOVA for repeated measures. Results showed a significant increase in $40-\mathrm{Hz}$ SSR power during stimulation condition compared to resting state condition at T5 $\left(F_{52,2}: 32.00 ; p<.000\right), \mathrm{T} 6\left(F_{52,2}: 30.61 ; p<.000\right)$ and $\mathrm{O} 2$ $\left(F_{52,2}: 23.08 ; p<.000\right)$.

The $40-\mathrm{Hz}$ power showed a moderate but significant correlation with cognitive performance as measured with ADAS-cog at T5 $(r=.43, p=.019)$ and T6 $(r=.38, p=.028)$. The correlation between $40-\mathrm{Hz}$ power at $\mathrm{O} 2$ and ADAS-cog was low and not significant $(r=.19, p=.064)$.

\section{Discussion}

The current study showed almost a universally high TRR and a significant difference in $40-\mathrm{Hz}$ SSR power between the patient groups. The correlations between the sessions ranged from 0.68 to 0.83 , which is high. Only the Pz electrode in the control group showed a moderate correlation (i.e. $0.54)$. These high correlations suggest that the $40-\mathrm{Hz}$ SSR can reliably be assessed in a cognitively impaired population.

40-HzHz SSR power was higher the AD group compared to $\mathrm{MCI}$ and control groups. Additionally, we also discovered a difference between the $\mathrm{AD}$ and $\mathrm{MCI}$ group. The difference between the $\mathrm{AD}$ and control group is in line with a previous MEG study by Osipova et al. (2006). A difference between $\mathrm{AD}$ and MCI with regard to $40-\mathrm{Hz}$ SSR power has not been reported before this study. The absence of a difference between MCI and controls might be related to the heterogeneous nature of the MCI concept (Visser and Brodaty, 2006). MCI not only includes patients in the prodromal stage of $\mathrm{AD}$, but also patients with other causes for cognitive impairment. Had we confined ourselves to amnestic MCI patients, who are more prone to progress to AD (Petersen, 2004), the difference between MCI and controls would probably have been larger. Previous EEG studies already showed that when focusing on alpha band power, there is a significant difference between progressive MCI patients and stable MCI patients (Huang et al., 2000; Luckhaus et al., 2008). Despite the absence of a significant difference between MCI and healthy controls, the $40-\mathrm{Hz}$ SSR power in the MCI group is in between that the $\mathrm{AD}$ and the control group. The correlations between $40-\mathrm{Hz}$ power and cognitive performance as measured by ADAS-cog varied between $r=.19$ and .43 . However, a previous study showed that theta, alpha and beta band power has a higher correlation with ADAS-cog (i.e. $\rho=.42-.53$ ) (Brinkmeyer et al., 2004). Despite the lower cor- 


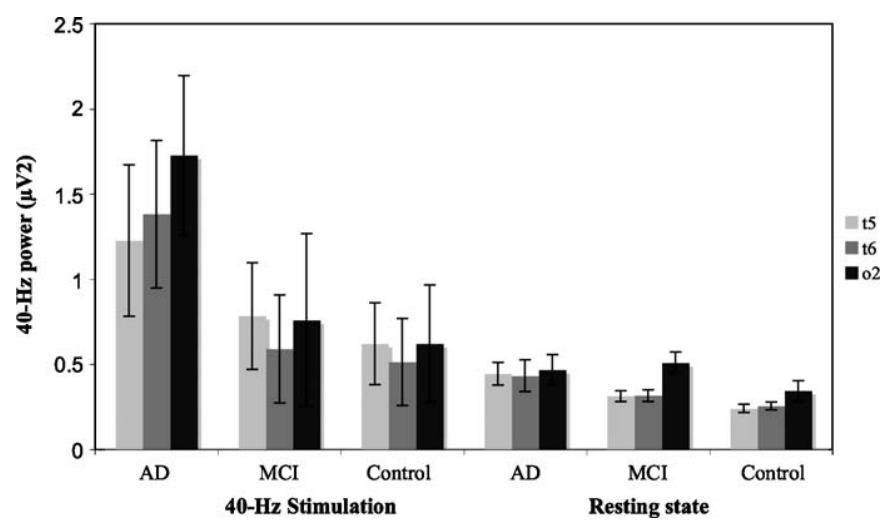

Fig. 1. The mean + S.E.M. 40-Hz SSR power for each group in stimulation condition (left) and resting state condition (right). In stimulation condition 40-Hz SSR power was higher in the AD group compared to controls at T5, T6 and O2. At T6 there was a difference between AD and MCI. During stimulation condition $40-\mathrm{Hz}$ SSR power was significantly higher than in resting state.

relation, the findings of the present study suggest that the $40-\mathrm{Hz}$ SSR power increases as the severity of the disease increases. Whether $40-\mathrm{Hz}$ SSR can be used to predict the progression of MCI to AD is at present not clear. The findings of this study suggest that this would be an interesting subject of future research.

In EEG studies of an elderly population differences in age can be a possible confounder of the results. Although the results show no significant differences between the groups with regard to age and pre-morbid intelligence, we performed a post hoc analysis to ensure that these parameters did not bias the results. Age and pre-morbid intelligence were entered as covariates in the GLM model and proved to have no effect on the group results. Another possible confounder in the $40-\mathrm{Hz}$ SSR measurements is the contamination with EMG. In a previous study we showed that when an extra EMG reduction procedure is performed, gamma band $(30-100 \mathrm{~Hz})$ power is reduced (van Deursen et al., 2008). Therefore in the current study, the same procedure was included in the preprocessing steps, which removed this possible confounder from our data.

A methodologically strong aspect of the current study was that only psychoactive drug naïve patients were included. Most drugs used in AD affect the cholinergic nervous system. Since acetylcholine seems to be involved in the regulation of the 40-Hz SSR, these types of drugs will bias the results when medicated $\mathrm{AD}$ patients are included. The cholinergic involvement in the regulations of $40-\mathrm{Hz}$ SSR has been suggested by a study that showed that scopolamine, which is a muscarine antagonist that is often used as a pharmacological model for $\mathrm{AD}$, increased $40-\mathrm{Hz}$ power in healthy young and elderly subjects (Ahveninen et al., 1999, 2002).

The location of the group differences indicates that the main difference was found in the auditory cortex, which is in agreement with a previous MEG study (Osipova et al., 2006). The auditory cortex has been proposed as the main generator of the $40-\mathrm{Hz}$ rhythm (Gutschalk et al., 1999) although thalamicocortical circuits also seem to play a role
(Ribary et al., 1991). The temporal cortex is one of the first areas to be affected by the neurodegenerative processes in AD (Braak and Braak, 1995). Therefore, the difference between the groups is most probably related to changes in the $40-\mathrm{Hz}$ generators that are located in the temporal cortex.

Increased 40-Hz SSR power in the auditory cortex of AD patients has previously been associated with decreased inhibition of the superimposed middle-latency auditory peaks that are related to sensory processing (Osipova et al., 2006). Dual-click sensory gating paradigms showed that in $\mathrm{AD}$ the second P50 peak is increased compared to healthy controls, which suggests impaired cortical inhibition (Cancelli et al., 2006; Jessen et al., 2001). The current results confirm these previous findings.

Cortical disinhibition in AD can be associated with dysfunction of the neurotransmitters gamma-aminobutyric acid (GABA) and glutamate (Jacob et al., 2008). There is variable evidence for dysfunction of GABA and glutamate in AD (Francis, 2003; Garcia-Alloza et al., 2006; Lanctot et al., 2004; Lowe et al., 1988). GABA seems to play an important role in the regulation of the $40-\mathrm{Hz}$ SSR, as administration of the GABA agonist temazepam attenuates the 40-Hz SSR (Jaaskelainen et al., 1999). The role of acetylcholine, GABA and glutamate in the regulation of the $40-\mathrm{Hz}$ rhythm is however not clearly understood and will need more attention in future research.

In sum, the current study showed that the $40-\mathrm{Hz}$ SSR power is higher in patients with AD compared to MCI subjects and healthy controls. The high TRR together with the correlation with cognitive performance suggest that the $40-\mathrm{Hz}$ SSR can reliably be used to measure disease progression.

\section{Conflict of interest}

All authors state that there were no conflicts of interest involved in this study. 


\section{Acknowledgements}

This work was financially supported by research agreement CSMD Ref No: 002509 from GlaxoSmithKline, Cambridge, UK. We thank Lieke Smits, MSc for her help with the collection of the data.

\section{References}

Ahveninen, J., Jaaskelainen, I.P., Kaakkola, S., Tiitinen, H., Pekkonen, E., 2002. Aging and cholinergic modulation of the transient magnetic $40-\mathrm{Hz}$ auditory response. Neuroimage 15 (1), 153-158.

Ahveninen, J., Tiitinen, H., Hirvonen, J., Pekkonen, E., Huttunen, J., Kaakkola, S., Jaaskelainen, I.P., 1999. Scopolamine augments transient auditory 40-Hz magnetic response in humans. Neurosci Lett. 277 (2), $115-118$.

Blessed, G., Tomlinson, B.E., Roth, M., 1968. The association between quantitative measures of dementia and of senile change in the cerebral grey matter of elderly subjects. Br. J. Psychiatry 114 (512), 797-811.

Boutros, N., Torello, M.W., Burns, E.M., Wu, S.S., Nasrallah, H.A., 1995. Evoked potentials in subjects at risk for Alzheimer's disease. Psychiatry Res. 57 (1), 57-63.

Braak, H., Braak, A., 1995. Staging Of Alzheimer's disease-related neurofibrillary changes. Neurobiol. Aging 16 (3), 271-284.

Brinkmeyer, J., Grass-Kapanke, B., Ihl, R., 2004. EEG and the test for the early detection of dementia with discrimination from depression (TE4D): a validation study. Int. J. Geriatr. Psychiatry 19 (8), 749-753.

Cancelli, I., Cadore, I.P., Merlino, G., Valentinis, L., Moratti, U., Bergonzi, P., Gigli, G.L., Valente, M., 2006. Sensory gating deficit assessed by $\mathrm{P} 50 / \mathrm{Pb}$ middle latency event related potential in Alzheimer's disease. J. Clin. Neurophysiol. 23 (5), 421-425.

Derix, M.M., Hofstede, A.B., Teunisse, S., Hijdra, A., Walstra, G.J., Weinstein, H.C., van Gool, W.A., 1991. CAMDEX-N: the Dutch version of the Cambridge examination for mental disorders of the elderly with automatic data processing. Tijdschr. Gerontol. Geriatr. 22 (4), 143-150.

Folstein, N., Folstein, S., McHugh, P., 1975. Mini-mental state: a practical method for grading the cognitive state of patients for clinician. J. Psychiatry Res. 12, 189-198.

Francis, P.T., 2003. Glutamatergic systems in Alzheimer's disease. Int. J. Geriatr. Psychiatry 18 (Suppl. 1), S15-21.

Galambos, R., Makeig, S., Talmachoff, P.J., 1981. A 40-Hz auditory potential recorded from the human scalp. Proc. Natl. Acad. Sci. U.S.A. 78 (4), 2643-2647.

Garcia-Alloza, M., Tsang, S.W., Gil-Bea, F.J., Francis, P.T., Lai, M.K., Marcos, B., Chen, C.P., Ramirez, M.J., 2006. Involvement of the GABAergic system in depressive symptoms of Alzheimer's disease. Neurobiol. Aging 27 (8), 1110-1117.

Gutschalk, A., Mase, R., Roth, R., Ille, N., Rupp, A., Hahnel, S., Picton, T.W., Scherg, M., 1999. Deconvolution of $40 \mathrm{~Hz}$ steady-state fields reveals two overlapping source activities of the human auditory cortex. Clin. Neurophysiol. 110 (5.), 856-868.

Hamilton, M., 1960. A rating scale for depression. J. Neurol., Neurosur., Psychiatry 23, 56-62.

Herrmann, C.S., Munk, M.H., Engel, A.K., 2004. Cognitive functions of gamma-band activity: memory match and utilization. Trends Cogn. Sci. 8 (8), 347-355.

Huang, C., Wahlund, L., Dierks, O., Julin, T., Winblad, P., Jelic, B.B., 2000. Discrimination of Alzheimer's disease and mild cognitive impairment by equivalent EEG sources: a cross-sectional and longitudinal study. Clin. Neurophysiol. 111, 1961-1967.

Jaaskelainen, I.P., Hirvonen, J., Saher, M., Pekkonen, E., Sillanaukee, P., Naatanen, R., Tiitinen, H., 1999. Benzodiazepine temazepam suppresses the transient auditory $40-\mathrm{Hz}$ response amplitude in humans. Neurosci. Lett. 268 (2), 105-107.
Jacob, T.C., Moss, S.J., Jurd, R., 2008. GABA(A) receptor trafficking and its role in the dynamic modulation of neuronal inhibition. Nat. Rev. Neurosci. 9 (5), 331-343.

Jessen, F., Kucharski, C., Fries, T., Papassotiropoulos, A., Hoenig, K., Maier, W., Heun, R., 2001. Sensory gating deficit expressed by a disturbed suppression of the P50 event-related potential in patients with Alzheimer's disease. Am. J. Psychiatry 158 (8), 1319-1321.

Joliot, M., Ribary, U., Llinas, R., 1994. Human oscillatory brain activity near $40 \mathrm{~Hz}$ coexists with cognitive temporal binding. Proc. Natl. Acad. Sci. U.S.A. 91 (24), 11748-11751.

Karakas, S., Basar, E., 1998. Early gamma response is sensory in origin: a conclusion based on cross-comparison of results from multiple experimental paradigms. Int. J. Psychophysiol. 31 (1), 13-31.

Lanctot, K.L., Herrmann, N., Mazzotta, P., Khan, L.R., Ingber, N., 2004. GABAergic function in Alzheimer's disease: evidence for dysfunction and potential as a therapeutic target for the treatment of behavioural and psychological symptoms of dementia. Can. J. Psychiatry 49 (7), 439-453.

Lowe, S.L., Francis, P.T., Procter, A.W., Palmer, A.M., Davison, A.N., Bowen, D.M., 1988. Gamma-aminobutyric acid concentration in brain tissue at two stages of Alzheimer's disease. Brain 111 (Pt. 4), 785799.

Luckhaus, C., Grass-Kapanke, B., Blaeser, I., Ihl, R., Supprian, T., Winterer, G., Zielasek, J., Brinkmeyer, J., et al., 2008. Quantitative EEG in progressing vs stable mild cognitive impairment (MCI): results of a 1-year follow-up study. Int. J. Geriatr. Psychiatry 23 (11), 1148-1155.

McKhann, G., Drachman, D., Folstein, M., Katzman, R., Price, D., Stadlan, E.M., 1984. Clinical diagnosis of Alzheimer's disease: report of the NINCDS-ADRDA work group under the auspices of department of health and human services task force on Alzheimer's disease. Neurology 34 (7), 939-944.

Osipova, D., Pekkonen, E., Ahveninen, J., 2006. Enhanced magnetic auditory steady-state response in early Alzheimer's disease. Clin. Neurophysiol. 117 (9), 1990-1995.

Petersen, R.C., 2004. Mild cognitive impairment as a diagnostic entity. J. Int. Med. 256 (3), 183-194.

Petersen, R.C., Doody, R., Kurz, A., Mohs, R.C., Morris, J.C., Rabins, P.V., Ritchie, K., Rossor, M., Thal, L., Winblad, B., 2001. Current concepts in mild cognitive impairment. Arch. Neurol. 8 (12), 1985-1992.

Reisberg, B., Ferris, S.H., de Leon, M.J., Crook, T., 1982. The Global Deterioration Scale for assessment of primary degenerative dementia. Am. J. Psychiatry 139 (9), 1136-1139.

Ribary, U., Ioannides, A.A., Singh, K.D., Hasson, R., Bolton, J.P., Lado, F., Mogilner, A., Llinas, R., 1991. Magnetic field tomography of coherent thalamocortical $40-\mathrm{Hz}$ oscillations in humans. Proc. Natl. Acad. Sci. U.S.A. 88 (24), 11037-11041.

Rosen, W.G., Mohs, R.C., Davis, K.L., 1984. A new rating scale for Alzheimer's disease. Am. J. Psychiatry 141 (11), 1356-1364.

Schmand, B., Geerlings, M.I., Jonker, C., Lindeboom, J., 1998. Reading ability as an estimator of premorbid intelligence: does it remain stable in emergent dementia? J. Clin. Exp. Neuropsychol. 20 (1), 42-51.

Tallon-Baudry, C., Bertrand, O., 1999. Oscillatory gamma activity in humans and its role in object representation. Trends Cogn. Sci. 3 (4), 151-162.

van Boxtel, M.P., Buntinx, F., Houx, P.J., Metsemakers, J.F., Knottnerus, A., Jolles, J., 1998. The relation between morbidity and cognitive performance in a normal aging population. J. Gerontol. 53 (2), M147-M154.

van Deursen, J.A., Vuurman, E.F., Verhey, F.R., van Kranen-Mastenbroek, V.H., Riedel, W.J., 2008. Increased EEG gamma band activity in Alzheimer's disease and mild cognitive impairment. J. Neural. Transm. 115 (9), 1301-1311.

Verhey, F.R., Houx, P., Van Lang, N., Huppert, F., Stoppe, G., Saerens, J., Bohm, L., De Vreese, A., Nordlund, P.P., DeDeyn, M., Neri, J., PenaCasanova, A., Wallin, E., Bollen, H., Middelkoop, M.C., Nargeot, M., Puel, U., Fleischmann, M., Jolles, J., 2004. Cross-national comparison and validation of the Alzheimer's Disease Assessment Scale: results from the European Harmonization Project for Instruments in Dementia (EURO-HARPID). Int. J. Geriatr. Psychiatry 19 (1), 41-50. 
Verhey, F.R., Jolles, J., Ponds, R.W., Rozendaal, N., Plugge, L.A., de Vet, R.C., Vreeling, F.W., van de Lught, P.J., 1993. Diagnosing dementia: a comparison between a monodisciplinary and a multidisciplinary approach. J. Neuropsychiatry Clin. Neurosci. 5 (1), 78-85.

Visser, P.J., Brodaty, H., 2006. MCI is not a clinically useful concept. Int. Psychogeriatr. 18 (3), 402-409 (discussion 409-414).
Whitham, E.M., Pope, K.J., Fitzgibbon, S.P., Lewis, T., Clark, C.R., Loveless, S., Broberg, M., Wallace, A., DeLosAngeles, D., Lillie, P., Hardy, P., Fronsko, R., Pulbrook, A., Willoughby, J.O., 2007. Scalp electrical recording during paralysis: quantitative evidence that EEG frequencies above $20 \mathrm{~Hz}$ are contaminated by EMG. Clin. Neurophysiol. 118 (8), 1877-1888. 